\title{
Future weather data for dynamic building energy simulations: overview of available data and presentation of newly derived data for Belgium
}

\author{
Delphine Ramon ${ }^{1 \text { [0000-0001-9467-6236] }}$, Karen Allacker ${ }^{10000-0002-1064-0795]}$, Nicole P.M. van \\ Lipzig $^{2}$, Frank De Troyer ${ }^{1[0000-0001-8042-6762]}$ and Hendrik Wouters ${ }^{3[0000-0002-2936-6407]}$ \\ ${ }^{1}$ Department of Architecture, Faculty of Engineering Science, KU Leuven, Belgium \\ ${ }^{2}$ Department of Earth and Environmental Sciences, Faculty of Science, KU Leuven, Belgium \\ ${ }^{3}$ Department of Forest and Water management, Faculty of Bioscience Engineering, UGent, Bel- \\ delphine.ramon@kuleuven. be
}

\begin{abstract}
As buildings have a relatively long life span, it is important to consider climate change in energy performance modelling. Good quality weather data are needed to obtain accurate results. This chapter discusses widely used methods to predict future weather data (dynamical downscaling, stochastic weather generators and morphing) and provides an overview of available weather datasets (multi-year, typical years, extreme years and representative years) for building simulations. A Flemish office building is used for a comparative analysis of the estimated heating and cooling load making use of one-year weather files (typical and extreme future climate conditions) derived from a recently developed convection-permitting climate model for Belgium. Climate models and weather generators are identified as the most preferred for the estimation of the average energy consumption and thermal comfort in average and extreme situations. Climate models have the advantage to better represent extreme weather events and climate differences due to territorial settings, while weather generators can generate multiple climate realizations. A combination of a typical year with an extreme cold and extreme warm year was found to result in an overall good representation of the energy need for heating and cooling in average and extreme weather conditions. Further, the influence of the methodological choices to extract one-year weather files (typical or extreme years) from the 30 -year climate data is highlighted as different results were obtained when different meteorological variables were considered for the creation of the one-year files.
\end{abstract}

Keywords: Future weather files, climate modelling, built environment, convection-permitting climate model, typical year, extreme year.

\section{$1 \quad$ Introduction}

People spend a lot of time in buildings protecting them from the outdoor weather. These buildings are affected to an important extent by the local weather. The heatwave of 
2003 caused thousands of excess deaths in France only [1], and indoor thermal discomfort is considered as one factor in this excess of deaths. Towards the future, an increase of temperature is expected and in particular an increase of the frequency of heatwave periods [2-4]. Heatwaves are also becoming more severe in urban areas due to the urban heat island effect [2], likely leading to comfort and wellbeing problems for occupants at a regular base and/or to an increase in electricity consumption for active cooling [5]. In the last decade, various researchers worldwide investigated the impact of climate change on the building energy performance [4, 6-17].

Buildings should be resilient to these climate changes without leading to comfort issues or structural damage. To investigate the performance of a building in a context of climate change, the full life cycle of the building should be considered. In order to predict the building energy performance in future, two crucial aspects are needed: (1) an appropriate energy simulation model that can accurately predict building performance and (2) good quality future weather data.

Three types of building energy simulations are currently used: static, semi-dynamic and dynamic simulations. In a dynamic energy simulation, a thermal balance is calculated for each timestep of the simulation. Based on this balance the heating and cooling demand as well as the thermal comfort can be defined. The thermal balance takes into account internal heat gains (people, appliances, lighting ...), outside weather conditions and the building characteristics (thermal capacity, insulation level, heating and cooling systems ...). The interaction of these parameters and their hourly variations are hence considered. A static energy simulation does not take into account all these dependencies or time variations. For example, to calculate the monthly heating demand in static simulations, monthly average temperatures are used. Static energy simulations hence allow to assess the average energy performance of a building (in a rather rough way), but do not allow to determine the thermal comfort as the latter requires hourly data and the variance of the different elements (e.g. internal gains and solar gains) of the thermal balance gain importance. Similarly, this variation is important to investigate a building in extreme weather conditions, e.g. when investigating peak energy demands or thermal discomfort. Semi-dynamic simulations take a shorter timestep, e.g. instead of monthly average temperature and solar gains, hourly temperature, hourly direct and indirect solar gains for an average day of each month. For these reasons, dynamic building simulations are more appropriate to assess building resilience towards climate change.

Dynamic energy simulations require weather data with at least hourly values, using for example an epw-format [18]. These weather files typically contain information about temperature, radiation (direct and diffuse), wind (direction and speed), rain, snow, humidity and pressure. In addition, it includes among others location related information such as time zone, elevation or average ground temperatures [18].

Depending on the goal of the building energy simulation, weather data should contain information about different weather conditions. If the simulation aims at investigating the overall energy consumption or thermal comfort, weather data representing the typical weather conditions is needed $[19,20]$. However, if the aim is to assess the energy consumption or thermal comfort in extreme conditions (i.e. extremely hot or cold), weather data representing those extreme conditions is required [19, 20]. A combination of typical weather data and extreme weather data in one representative dataset 
could combine both assessments in one simulation [21]. To size HVAC systems design days or short periods are used $[19,20]$.

When aiming at climate resilient buildings, future weather data are needed. In order to take into account the inherent uncertainties of climate change, it is important to consider the various possible climate realizations [22].In the last years, appropriate weather data for the assessment of buildings under climate change have been researched [2332]. Several future weather files / datasets and methodologies were developed. A first methodological option is to use a weather file from a different location, more specifically from a location which currently has similar climate conditions as expected for the building location in the future (analogue scenario method) [33, 34]. A second option, often used in practice, is to select a year from the past that is warmer than normal to represent the future climate. Thirdly, general circulation models $(150-600 \mathrm{~km}$ spatial resolution $[22,35])$ taking into account future climate scenarios can be used. To be useful for building simulations, downscaling to a relevant spatial resolution for building simulations is needed, e.g. by dynamical downscaling, interpolation, stochastic weather generators or morphing $[33,36]$.

This paper aims at providing insight in the various methods to predict future weather data and in the available weather datasets appropriate for the Belgian context. The aim is moreover to present recently developed data based on the dynamical downscaling of regional climate models for Belgium and to show their potential to be used in building simulations through a comparative analysis with other datasets (e.g. representative) extracted from these models.

The chapter is structured as follows. In section 2, widely used methods (section 2.1) and available datasets (section 2.2) are presented and their appropriateness to predict the building energy performance in a context of climate change (section 2.3) are discussed. In the latter section, the appropriateness is linked to the specific simulation goal (heating and cooling demand, thermal comfort evaluation) excluding building simulation for sizing of HVAC. Section 3 presents the newly developed future weather data and compares these with other weather datasets extracted from these data. The weather data are moreover applied in the energy simulation of a simple case study (office building). The final section discusses the outlook for weather data and their requirements to assess buildings in the context of climate change.

\section{Future weather data methods and data formats}

This section provides an overview of currently available future weather data types. A three-step approach is followed. Firstly, an overview is given of methodologies to obtain future weather data. Secondly, various weather datasets for building energy simulations are discussed. Finally, the advantages and limitations of the various methods and formats, linked to a certain energy simulation goal, are summarised. 


\subsection{Future weather data methodologies}

As discussed before, the analogue scenario method and the selection of a warmer year from the past can be used for building simulations in a future climate context. However, the important role of solar radiation however makes it hard to find suited weather files as this depends on the latitude of the location. Moreover, the change of solar radiation seems rather small in current climate change scenarios. Further, both methods assume similar weather behavior in future as to date while it is expected that frequency of events (e.g. heatwaves) will change in time [2-4]. Therefore, these are not further discussed in this chapter.

Ongoing research about future weather data for building simulations make in general use of General Circulation Models (GCMs) to gain insights in future climate behaviour [23-31]. This type of climate models simulate the state and evolution of the atmosphere, including the atmospheric circulation and energy exchanges in terms of radiation, heat and moisture. They also simulate the processes related to cloud formation and precipitation, and take into account the interaction with the ocean and the land [22].

Climate models are typically used to construct possible trajectories of the future climate. These trajectories particularly take into account the radiative forcing established by the emission of greenhouse gas and aerosols from human activities and natural processes. The most well-known emission scenarios are the Representative Concentration Pathways (RCPs) used by the Intergovernmental Panel on Climate Change (IPCC). They comprise of four scenarios, namely RCP2.6, RCP4.5, RCP6.0 and RCP8.5, which are named after radiative forcing established by the greenhouse gas emissions in the year 2100 relative to pre-industrial values $\left(+2.6,+4.5,+6.0\right.$, and $+8.5 \mathrm{~W} / \mathrm{m}^{2}$, respectively) [37]. Climate models are also used for studying the climate of the past, e.g. to provide climate information for regions where observations are not available.

It should be noted that climate models are not designed to reproduce the order of consecutive weather conditions, since climate models are not constrained by observations. However, they are capable of representing (multi-)decadal climate statistics, such as the mean or variance of temperature of a particular season, or the frequency or mean intensity of heat waves. Climate models are available for different time spans (up to several decades) but are usually treated for periods of 30 years as the World Meteorological Organization considers that climate statistics converge over this time span [38].

GCMs provide climate information on the global scale with a typical spatial resolution of $150-600 \mathrm{~km}[22,35]$. When these models are hence used for building energy simulations, the propagation of climate change and related weather extremes at the local level are not taken into account. This is problematic as many buildings are located in cities and are hence affected by urban heat islands. If to be used for building energy simulations, downscaling of the GCMs is needed.

To obtain downscaled weather data from GCMs, Belcher et al. [33] describe four methods: (1) dynamical downscaling (2) stochastic weather generators (3) morphing; and (4) interpolation. Wilby and Wigley [36] further mention regression and weather pattern methods as additional downscaling techniques. A literature review of on ongoing research [23-31] the first three methods are commonly used to create weather data used in building simulations. These are further discussed in the subsequent paragraphs. 


\section{Dynamical downscaling}

During the last two decades, GCMs were downscaled to regional climate models (RCMs) by making use of a nesting strategy to obtain climate information at a resolution of $10-100 \mathrm{~km}$. The RCM domain (which covers a smaller region of the world) is nested in the GCM domain. The RCM domain with a finer grid resolution is run with the GCM as initial condition. During the model run, the GCM provides the boundary of the domain climate information. Downscaling of GCMs typically results in an ensemble of RCMs where for each model simulation the same radiative forcing scenarios are used [22]. This approach however results in internally generated climate variability different for each member due to small perturbations of the initial conditions. result and hence in different climate realizations in one ensemble.

RCMs better represent the regional effects from the orography and the heterogeneity of the soil, vegetation cover and coastal effects. Some of these RCMs were implemented in building simulations by amongst others Nik et al. [21,39] and Kikumoto et al. [40]. Nevertheless, RCMs do not yet fully resolve urban effects, while deep atmospheric convection needs to be parameterized as well.

The latter two shortcomings of RCMs have been recently resolved by further downscaling the RCMs by means of convection-permitting models (CPMs) providing the meso-scale climate information at a resolution of $1-4 \mathrm{~km}$. As such, cities and deep convection become explicitly resolved [41-43] and as such these CPMs allow to take such information into account. CPMs are hence promising for building simulations as they provide a better representation of local climate (change) compared to RCMs [44].

CPMs require a high computational time and they are typically available for only one or a few realizations of the future climate. As such, CPMs lack information on the uncertainty of the climate change signal stemming from either physical parameterizations or climate variability. They furthermore are only available for a few regions in the world (e.g. Belgium, UK, Alps, Kilimanjaro region, northwestern Pacific Ocean, Sahel regions [44]).

\section{Stochastic Weather generators}

Stochastic weather generators are defined by Wilks and Wilby as "statistical models which can fill in missing data or produce indefinitely long synthetic weather series by simulating key properties of observed meteorological records (i.e. daily means, variances and covariances, frequencies, extremes, etc.)" ([45]: p. 329). Originally, weather generators were mainly used in the field of agriculture (e.g. crop production), climate change studies, hydrology and ecology. Later, several weather generators were developed to generate future weather data to be used in building energy simulations, amongst others by van Paassen and Luo [46], RUNEOLE by Adelard et al. [47] and the UKCP09 weather generator by Eames et al. [25, 28].

Precipitation is most often the primary variable for the stochastic model of the weather generator [28, 48]. Based on the methodology of Hutchinson [49] a two-step approach is applied. In a first step, the daily precipitation is modelled based on the current climate data. Based on the fact if a day is wet or dry and the weather conditions of the previous day, the other weather variables are generated (mostly temperature and 
radiation). Parameters such as wind are derived from the latter. Different model parameters for each month are used to include the seasonal variations of the meteorological parameters $[28,48,49]$.

An important advantage of the weather generator methodology is that it allows to integrate the distribution used for the climate change signal and to account for potential changes in weather patterns and climate variability. Some weather generators (e.g. UKCP09 weather generator) furthermore allow to investigate the climate change uncertainty by considering various possible climate realizations [27, 28]. Multiple climate realizations can be created by randomly selecting a climate change signal at the beginning of the weather generation [28].

However, statistical relations between variables as well as distributions are based on baseline data given to the model to generate future data from. Hence, large amounts of data are needed to train the model [33]. Further, using stochastic weather generators becomes difficult when statistical relations between meteorological variables are missing in the baseline data because weather events did not happen in that period. The mathematical basis can moreover result in a limited representation and parametrization of climate physics, hence possibly leading to meteorological inconsistencies [33].

The weather generator allows a high spatial resolution (e.g. up to $5 \mathrm{~km}$ in the case of the UKCP09 weather generator). The climate change signal as such however often has a lower spatial resolution (e.g. $25 \mathrm{~km})$ [25]. Hence, a spatial variance in the climate change signal in the area of 25 by $25 \mathrm{~km}$ caused by territorial settings (e.g. urban versus rural area) is not considered when further downscaling $[2,50,51]$. With this method, there is moreover no correlation between two time-series generated for two adjacent grid cells as a point-based process is used [25].

\section{Morphing}

Belcher et al. [33] presents a methodology for the adjustment of time series towards the future, called 'morphing'. Current weather data are used as baseline and monthly climate change signals given by a GCM or RCM are used for morphing the current data. Depending on the climate variable and expression of the climate change signal (absolute, relatively), three operations are used to morph data: (1) shifting (2) scaling and (3) shifting and scaling combined [33]. Shifting is applied when the change is expressed absolutely, while scaling is used when a change is relatively expressed. Further, scaling is also used for variables that can be 'switched off' (e.g. irradiation). If both the mean and the variance of a variable change over time, shifting and scaling are combined. Shifting changes the mean, while scaling has an influence on the variance of the weather variable.

Some requirements for baseline weather data were pointed out by Belcher et al. [33] Firstly, the baseline data should represent the weather conditions for that period. Ideally the baseline data is averaged data for a period of 30 years [38]. Secondly, as the climate change signal is expressed against a certain period in time, the baseline data used should be representative for the same period. If these periods do not correspond, the generated weather data can under- or overestimate the climate change impact as pointed out by Kolokotroni et al. [52]. Thirdly, as the climate change signal is mostly expressed as a 
mean change signal, it is important to use averaged weather data as baseline to avoid under- or overestimation.

The morphing methodology is used amongst others by Chan [30], Kolokotroni et al.[52], CIBSE [53] and Ferrari et al. [54]. In the UK, the Climate Change Weather Generator tool (CCWeatherGen tool or CCWorldWeatherGen for outside the UK) was created based on this morphing methodology making use of the $\mathrm{HadCM}^{1} \mathrm{GCM}$ for the A2 emission scenario ${ }^{2}[23,24]$. Multiple studies moreover used this tool for climate change impact studies $([13,52,55])$.

An advantage of the morphing methodology is the low computational time. Various climate change scenarios can hence easily be applied. An important drawback of the morphing method is that the future weather data have the same character and variability as the current weather data [33] and hence any changes in frequency of (extreme) weather events, although expected [2, 3], are not considered. In addition, the mathematical basis of the method results in a limited representation and parametrization of climate physics possibly leading to meteorological inconsistencies [33]. This mostly leads to a limited representation of extreme weather events [48]. Jentsch et al. [24] furthermore point out that morphing data with GCMs tends to underestimate the climate change and they recommend to use RCM data for morphing if possible .

\subsection{Weather datasets}

Multi-year datasets

As mentioned before, climate models are typically multi-year datasets, usually covering periods of 30 year. Also weather generators can result in multi-year datasets [28]. The advantage of longer periods of data is the likelihood that they are covering both typical and extreme weather conditions for that period [38]. Such multi-year (30) datasets result in a high computational time if used in building simulations.

In order to reduce the computational time, weather data files for selected years can be developed. In building energy simulation, very often one-year weather data files are used, representing typical years or extreme years. Additionally, a combination of several one-year weather data files can be used. This is for example proposed by Nik [21] who proposes to use a combination of a typical year, an extreme cold and an extreme warm year. The various types of weather data files for a selected number of years are discussed in the subsequent sections.

\section{Typical years}

Typical years are fictive years consisting of representative typical months [19] which are selected by comparing the distribution of each month with the long-term distribution of that month for the observations available (the Finkelstein-Schafer statistics [56]). When defining a typical year, various meteorological variables can be focused on and various relative importance (weighting factor) can be used for those variables.

\footnotetext{
${ }^{1}$ Hadley Centre Coupled Model, version 3

${ }^{2}$ Medium-high emission scenario. One of the scenarios before the development of RCP scenarios to be used in GCMs for climate change.
} 
Various methods ([21, 57-62]) exist within this type of weather data, and lead to various weather data files, such as Test Reference Year (TRY) [63], International Weather year for Energy Calculations (IWEC) [61, 64, 65] or a Typical Meteorological Year (TMY) [60].Typical years are often used to estimate the average energy use of a building [19].

Typical years can either be based on observational data or data from a climate model. If these are based on observational data, the period for which the weather files are created depend on the available observational data for that specific location. Moreover, the locations for which such weather files can be derived, is restricted to locations where observational data are available. Nevertheless, it is possible to create typical year data for locations without observational data by means of interpolation of the observed data of several relevant other locations. This is for example the case for the Meteonorm Typical Years [66]. If typical years are derived from climate model datasets, the amount of typical years for a certain region depend on the spatial resolution of the climate model. The typical downscaled year (TDY) developed by Nik [27] is an example of a typical year based on climate model data.

For Belgium, the existing typical years (Test Reference Year or TRY [63], International Weather year for Energy Calculations or IWEC [64, 65] and Meteonorm Typical Years [66]) are based on observational data. These cover at least one decade [67, 68] and are available for three locations (Ostend, Uccle and Saint-Hubert) with the exception of the Meteonorm data. The Meteonorm software moreover allows to extract a typical year applying different methodologies (i.e. TMY2, TRY DWD, TRY DWD 1.1 [69] and TMY3 [70]).

A selection of typical year methods used in building simulations is summarized in Table 1. The table provides an overview of the meteorological variables considered in the basic dataset to define the typical year. Originally, the TRY (first one in the table) consisted of a selected single year out of a period of observations [57] and hence not of a combination of representative typical months from different years. Later, it evolved to a compilation of representative typical months, similar to the other methods in the table. For some of the methods, the considered variables and weighting scheme moreover evolved over the years (e.g. Typical Meteorological Year 2 or TMY2 weather format is adjusted from the TMY format adapting the weighting of the dry-bulb temperature and humidity [71]). The variables considered moreover sometimes differ within one method in order to account for the most important variables in a specific location (e.g. UK-TRY and ISO-TRY) [57, 58, 72]. Finally, an evolution of methods has been noticed due to the (non-)availability of solar data or more complex solar models to generate solar data over time $[60,61]$ (e.g. TMY2 included a more complex solar model than TMY [71]). 
Table 1. Selection of typical years used in building simulation

\begin{tabular}{|c|c|c|}
\hline Acronym & Complete name & Weather variables + weights (in \%) \\
\hline TRY* & Test Reference Year [57-59] & $\begin{array}{l}\text { First step equal weighting of T, R and hu- } \\
\text { midity; Second step Wspd }\end{array}$ \\
\hline TMY* & $\begin{array}{l}\text { Typical Meteorological Year } \\
{[60]}\end{array}$ & $\begin{array}{l}\mathrm{T}_{\min }(5 \%), \mathrm{T}_{\max }(5 \%), \mathrm{T}_{\text {mean }}(30 \%), \mathrm{TD}_{\min } \\
(2.5 \%), \mathrm{TD}_{\max }(2.5 \%), \mathrm{TD}_{\text {mean }}(5 \%), \\
\mathrm{Wspd}_{\max }(5 \%), \mathrm{Wspd}_{\text {mean }}(5 \%), \mathrm{R}(40 \%)\end{array}$ \\
\hline IWEC* & $\begin{array}{l}\text { International Weather Year for } \\
\text { Energy Calculations }[61,64 \text {, } \\
65]\end{array}$ & $\begin{array}{l}\mathrm{T}_{\min }(5 \%), \mathrm{T}_{\max }(5 \%), \mathrm{T}_{\operatorname{mean}}(30 \%), \mathrm{TD}_{\min } \\
(2.5 \%), \mathrm{TD}_{\max }(2.5 \%), \mathrm{TD}_{\text {mean }}(5 \%), \\
\mathrm{Wspd}_{\max }(5 \%), \mathrm{Wspd}_{\text {mean }}(5 \%), \mathrm{R}(40 \%)\end{array}$ \\
\hline $\mathrm{TDY}^{* *}$ & Typical Downscaled Year [21] & $\mathrm{T}$ \\
\hline WYEC* & $\begin{array}{l}\text { Weather Year for Energy Calcu- } \\
\text { lations }[62,73]\end{array}$ & $\mathrm{T}, \mathrm{TD}, \mathrm{R}$, precipi \\
\hline \multicolumn{3}{|c|}{$\begin{array}{l}\text { Notes: } \\
\text { (1) } T=\text { dry-bulb temperature, } T D=\text { dew-point temperature, Wspd }=\text { wind speed, } R=\text { radiation. } \\
\text { (2) Weather variables and related weighting factors changed over time for some of the methods and/or } \\
\text { differ for different locations. } \\
\text { (3) *: methodology originally based on observations } \\
\text { (4) **: methodology originally based on climate models }\end{array}$} \\
\hline
\end{tabular}

\section{Extreme years}

To assess the robustness of buildings to extreme weather conditions, to size HVAC systems or to perform climate uncertainty studies, insights in the variability of the climate and the occurrence of more extreme weather events are needed [4,9]. An extreme or near-extreme year can be used to assess the building for these purposes. Currently, extreme years are one-year weather data files which either include an extreme summer (e.g. Design Summer Year (DSY)) or winter (e.g. Extreme Cold Year (ECY)) or combination of both (e.g. Extreme Meteorological Year (XMY)).

There are several ways to select/compose an extreme year. A first approach uses a similar methodology as for defining typical years (i.e. making use of the FinkelsteinSchafer statistics). Instead of searching for the most representative typical months, the most deviating months are selected or a certain percentile in the distribution is selected $[21,74]$. For example, an XMY is defined by using the same approach as for defining a TMY. Although the approaches to define an XMY and TMY consider the same meteorological variables and weighting scheme [54], this is not always the case. The considered meteorological variables and related weighting factors for defining extreme years sometimes differ from the ones used to define a typical year (e.g. an Untypical Meteorological Year applies the same methodology but different weighting than the Weather Year for Energy Calculations version 2 [32, 62]). The Meteonorm software allows to select a P10 (minima) or P90 (maxima) year which have the probability to happen once a decade [66].

A second approach selects the extreme year based on a calculated value. The DSY calculates for example the average dry-bulb temperature for the summertime [74] while 
a Hot Summer Year (HSY) calculates the weighted cooling degree-hours ${ }^{3}$ (WCDH) $[31,75]$ to select a year. The use of one calculated value has some limitations. The DSY, for instance, represents a year with a warm summer based on the average monthly temperature for April to September and risks to neglect a summer with critical heat wave periods if the average temperatures are lower for the latter [34, 75]. It should furthermore be noted that an extreme year does not provide insights in the average discomfort to be expected on yearly basis. For example, a DSY is an extreme warm year to be expected to happen once each 8 years [34].

Similar as with typical years, extreme years can be created based on observational data, climate models or weather generator output. For Belgium, the existing extreme years are based on observations (the Meteonorm P10 and P90 years for the locations of Uccle, Ostend and Saint-Hubert). A selection of extreme weather years which are commonly used in building simulations are summarized in Table 2.

Table 2. Selection of Extreme Weather Years used in building simulation

\begin{tabular}{|c|c|c|}
\hline Acronym & Complete name & Weather variables + weights (in \%) \\
\hline DSY* & Design Summer Year [75] & Average $\mathrm{T}$ for period April-September \\
\hline $\mathrm{XMY}^{*}$ & $\begin{array}{l}\text { Extreme Meteorological } \\
\text { Year [54] }\end{array}$ & $\begin{array}{l}\mathrm{T}_{\min }(5 \%), \mathrm{T}_{\max }(5 \%), \mathrm{T}_{\operatorname{mean}}(30 \%), \mathrm{TD}_{\min } \\
(2.5 \%), \mathrm{TD}_{\max }(2.5 \%), \mathrm{TD}_{\text {mean }}(5 \%), \\
\mathrm{Wspd}_{\max }(5 \%), \mathrm{Wspd}_{\text {mean }}(5 \%), \mathrm{R}(40 \%) \\
\text { (based on } \mathrm{TMY})\end{array}$ \\
\hline $\mathrm{UMY}^{*}$ & $\begin{array}{l}\text { Untypical Meteorological } \\
\text { Year [32] }\end{array}$ & T, R, Wspd (based on WYEC) \\
\hline $\mathrm{H}$ & Hot Summer Year [31] & $\begin{array}{l}\text { Highest WCDH (HSY-1) or most hours of } \\
\text { PET }^{4} \text { over } 23^{\circ} \mathrm{C} \text { (HSY-2) }\end{array}$ \\
\hline $\mathrm{EWY}^{* *}$ & Extreme Warm Year [21] & $\mathrm{T}$ \\
\hline $\mathrm{ECY} * *$ & Extreme Cold Year [21] & $\mathrm{T}$ \\
\hline DRY* & Design Reference Year [76] & $\begin{array}{l}\mathrm{T}, \mathrm{R} \text {, humidity, wind speed (weather gen- } \\
\text { erator combined with weighting scheme) }\end{array}$ \\
\hline $\mathrm{P} 10 / \mathrm{P} 90 *$ & $\begin{array}{l}\mathrm{P} 10(\text { cold }) / \mathrm{P} 90 \text { (warm) ex- } \\
\text { treme year }[66]\end{array}$ & $\mathrm{T}, \mathrm{R}$ \\
\hline \multicolumn{3}{|c|}{$\begin{array}{l}\text { Notes: } \\
\text { (1) } T=\text { dry-bulb temperature, } T D=\text { dew-point temperature, Wspd }=\text { wind speed, } R=\text { radiation. } \\
\text { (2) Weather variables and related weighting factors changed over time for some of the methods and/or } \\
\text { differ for different locations. } \\
\text { (3) *: methodology originally based on observations } \\
\text { (4) **: methodology originally based on climate models }\end{array}$} \\
\hline
\end{tabular}

\footnotetext{
${ }^{3}$ Defined as "the cumulative squared hourly difference between the outdoor dry-bulb temperature and the adaptive thermal comfort temperature" ([75]: p. 1)

${ }^{4}$ Physiologically Equivalent Temperature [84]
} 


\section{Representative datasets}

The above described typical and extreme years are combined by Nik [21] in so-called representative datasets. Nik synthesizes three years out of a multi-year period, extracting a typical and an extreme cold and warm year from RCMs (multiple if available). A typical downscaled year (TDY) is extracted representing the typical conditions of the full period. Further an extreme cold and extreme warm year are extracted representing respectively coldest and warmest conditions from the considered period. To derive these three years a similar methodology is used as the one for the TMY, making use of the Finkelstein-Schafer statistics. In this case temperature is considered as variable to select the most extreme/typical months. This approach moreover allows to consider one or several future climate scenarios.

\subsection{Recommendations for the use of future weather data for building energy simulations}

When aiming at designing climate resilient buildings, various aspects can be investigated, ranging from the average energy consumption and thermal comfort to resilience in extreme weather conditions. Depending on the goal of the study, the most appropriate weather data need to be selected. When investigating the average energy consumption and thermal comfort, typical years are preferred, while to ensure resilience in extreme weather conditions, multi-year datasets or extreme weather years are better suited.

It is furthermore recommended that multi-year datasets, whether used directly or used for deriving extreme weather years from them, should cover a sufficiently long period (typically 30 years) to include the variability of the climate. When extreme weather data files are used it is furthermore important to select the appropriate one(s) for the goal of the study as some files rather represent years with high summer temperatures and not necessarily years with higher occurrence of extreme weather events, or the other way around.

As discussed in section 2.1, various methods exist to create future weather data from which then typical or extreme years can be derived. Each of the existing methods has its strong points and limitations. It is hence not only important to select the most appropriate weather data file (typical versus extreme, or a combination of both), but also to select the most appropriate method used to create the future weather data, in line with the goal of the study. While morphing is suited to investigate the average energy performance in a future climate realization, the fact that the baseline data is averaged data and climate change signal a mean change, makes it less suited for the assessment in extreme conditions. Dynamically downscaled climate models can be used for both average as extreme assessment purposes. In particular, when downscaled to convection-permitting scale $(<4 \mathrm{~km})$, these models are interesting to be used for estimation of the average energy consumption and thermal comfort in average and extreme situations. These models have an improved performance of the physical process, urban effects (e.g. urban heat island effect) and climate change signal. However they only represent one future climate realization. 
As climate change is inherently linked with uncertainties, considering different possible climate realizations is of major importance to design robust buildings. When addressing uncertainties is part of the research goal, probably the weather generators are the most appropriate. Weather generators are able to produce various climate realizations based on several climate change scenarios. Nevertheless, their spatial resolution is often coarser and more important meteorological variables are based on their statistical and mathematical relations which could result in meteorological inconsistencies.

Research focusing on building energy simulations with future climate data in the Belgian context is rare. In 2015, a convection-permitting climate model for Belgium for the end-of-the-century became available. A 30-year weather data file was derived from this model to be used for building energy simulations [77]. However, the 30-year data resulted in high computational time. Therefore a synthesized dataset has been derived from this 30-year dataset representing a typical and extreme cold and warm year. In Section 3 this synthesized dataset (TDY, ECY and EWY) is presented and compared with other typical and extreme years (TMY and DSY) extracted from the 30-year dataset. Comparisons are made for both the current and future climate perspective. The new and existing datasets are moreover used in a simple case study to investigate differences in results obtained.

\section{Future weather data for the Belgian context, applied to an office building}

\subsection{Building Energy Model}

A cellular office from a representative Flemish office building is simulated for this study making use of the dynamic energy simulation program EnergyPlus v8.7. The building has a concrete structure and a high insulation level (average U-value of 0.42 $\mathrm{W} / \mathrm{m}^{2} \mathrm{~K}$ ) [33]. A more detailed overview of the building elements is given in Table 3. A cellular office room located in the middle of the building is chosen for the simulations (Fig. 1). The temperature of internal walls, floors and ceilings is assumed to be the same at both sides of those elements. Heat can be accumulated in those elements and dissipated later, but there is no resulting flow. This is only a good assumption if the use of the adjacent rooms is similar to the room studied, leading to only small temperature differences between the rooms. To study the effect of orientation, the model is run for four orientations, the glazed façade facing north, east, south and west. 
Table 3. Building element composition

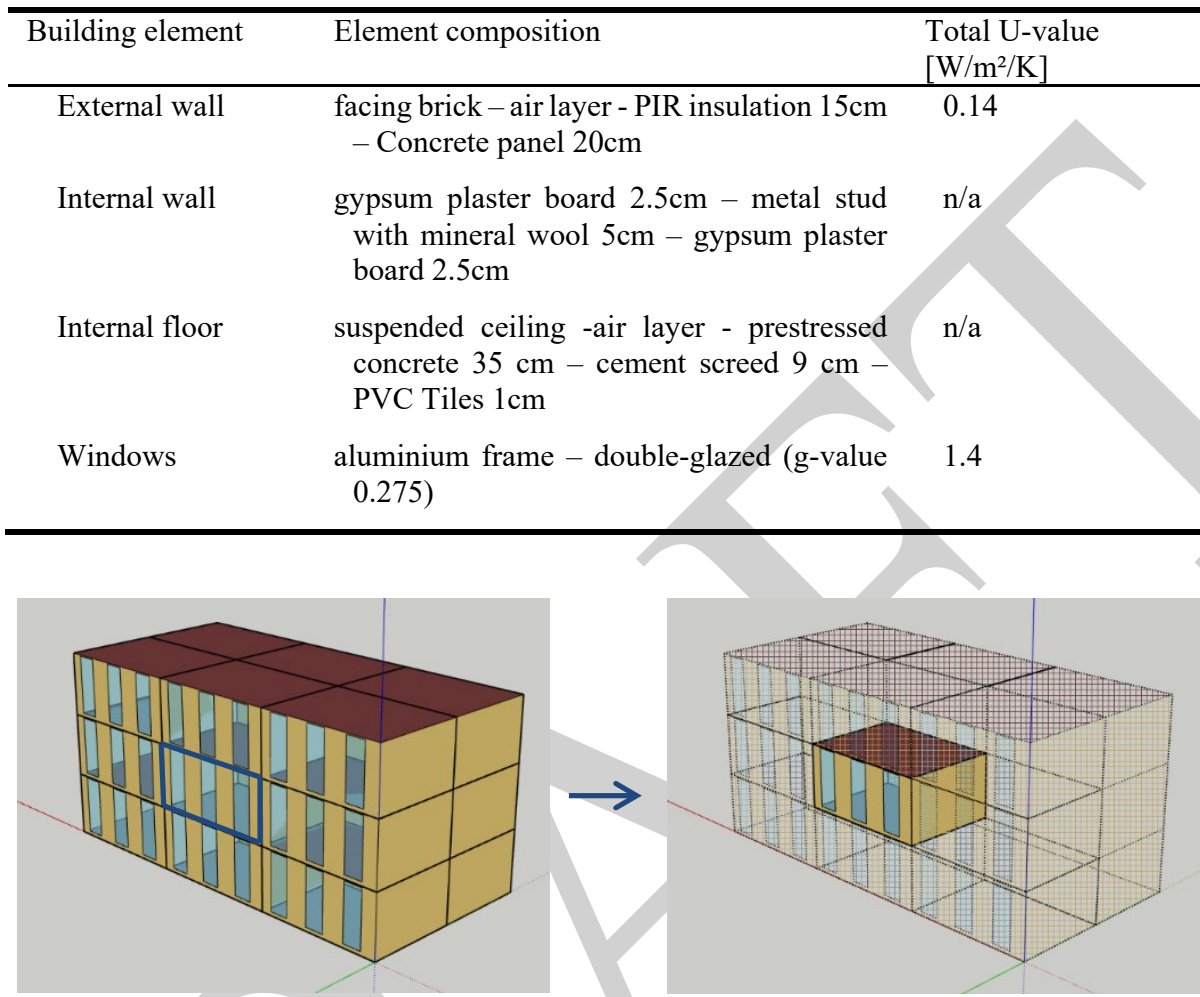

Fig. 1. Simulation setup: schematic building and considered office-room

The schedules for occupancy, lighting and equipment in the office room are modelled based on the NCM modelling guide [78]. The number of people per zone is defined in terms of area per person based on the architectural plans with a metabolic rate of 117 $\mathrm{W} /$ person $[79,80]$. Lights are modelled based on the lighting level (Watts) installed in the building. The office equipment is set to a load of $11.77 \mathrm{~W} / \mathrm{m}^{2}$ and a radiant fraction of 0.2 [80]. For the HVAC system, an ideal air loads system with unlimited capacity is implemented to get insights in the increase/decrease of energy to keep the room comfortable. Because of the unlimited capacity, heating and cooling is performed till the setpoints are met. The operative temperature (average of air temperature and surface temperature of walls, ceiling and floor) is used to control the ideal air loads system. Heating and cooling are assumed all year long. The heating setpoint is set on $22^{\circ} \mathrm{C}$ during occupancy and $15^{\circ} \mathrm{C}$ for other moments. Cooling is set to $24.5^{\circ} \mathrm{C}$ during the day and $35^{\circ} \mathrm{C}$ during the night and weekend for the summer period and heating season.

\subsection{Description and analysis of weather data used}

Several weather files were extracted for Uccle, centrally located in Belgium $(120 \mathrm{~km}$ from coast, $104 \mathrm{~m}$ above sea level). 
Firstly, two EC-Earth ${ }^{5}$ driven Convection Permitting Models (CPMs) are used [81]. The CPM uses COSMO-CLM ${ }^{6}$ (version 5.0) as regional climate model. A two-step nesting strategy is used to obtain the model with a $2.8 \mathrm{~km}$ horizontal resolution for the Belgian domain. In a first step, the $12 \mathrm{~km}$ resolution RCM simulation was nested in the EC-Earth domain and in a second step the $2.8 \mathrm{~km}$ resolution simulation was nested in the $12 \mathrm{~km}$ simulation [82]. To incorporate the local characteristics and the three-dimensional structure of the urban canopy, the CPM model is extended with the urban landsurface scheme TERRA_URB (v2.0) making use of the SURY (Semi- empirical URban canopY) parametrization [83]. TERRA_URB calculates radiation, heat and moisture fluxes between the urban environment and the atmosphere based on the bulk parameters (e.g. heat conductivity, albedo, aerodynamical roughness length ...). In addition, SURY translates the urban canopy parameters (e.g. building height, roof fraction, albedo, heat conductivity ...) into bulk parameters used in the climate models [83]. The model systematically evaluated and found to reproduce both the observed coarse temperature and the urban heat islands of the study domain very well in general, and the hourly and daily variability in particular [2]. From the model simulation an epw file is extracted for the 30-year period 1975-2004 (further referred to as EC-Earth) and the 30-year period 2069-2098 (further referred to as EC-Earth Future) based on the methodology described in [77]. The first year is each time used as a spin-up for the simulations. For the future time period, the climate change scenario chosen is one of the 16 EC-Earth members specified for the RCP8.5 scenario which has the most median climate change signal regarding temperature, precipitation and widespread circulation patterns for Belgium $[22,82]$.

Fig. 2 shows the temperature distribution for both periods. It is clearly visible that the mean monthly temperature increases over the full year (with an average increase of $2.9^{\circ} \mathrm{C}$ over the 12 months). For July the increase of the mean temperature even reaches a difference of $3.8^{\circ} \mathrm{C}$. The increase of the monthly minimum and maximum temperature is slightly more extreme than the increase of the monthly mean temperature. For August, the monthly maximum temperature increases even with $4.9^{\circ} \mathrm{C}$ towards the future. For February, the monthly minimum temperature increases with $5.2^{\circ} \mathrm{C}$.

5 EC-Earth is a global climate model developed by an European consortium [81].

6 Consortium for small scale modelling in Climate mode is a regional climate model [82] 


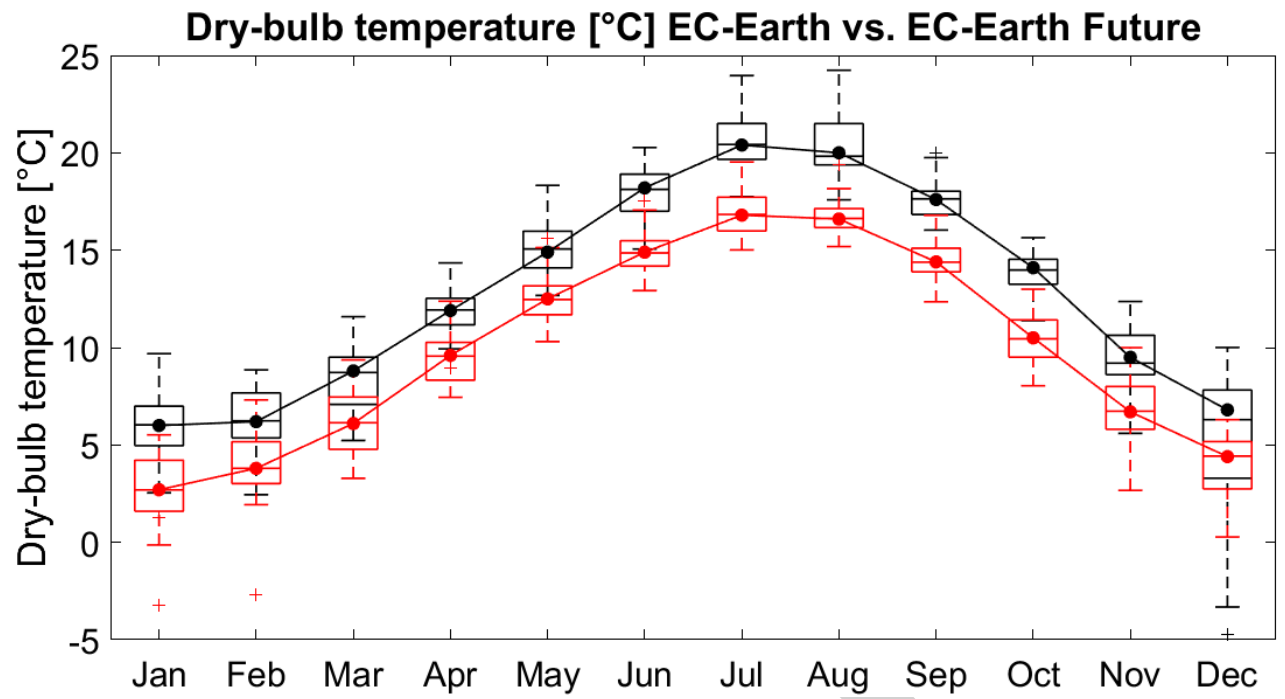

Fig. 2. Distribution monthly dry-bulb temperature EC-Earth (red) and EC-Earth Future (black)

For radiation, Fig. 3 shows an increase of radiation during summer (May- September) and a decrease for the rest of the year (October-March) with exception of November. The increase and decrease are caused by a change in the direct component of the radiation, while the diffuse component remains the same.

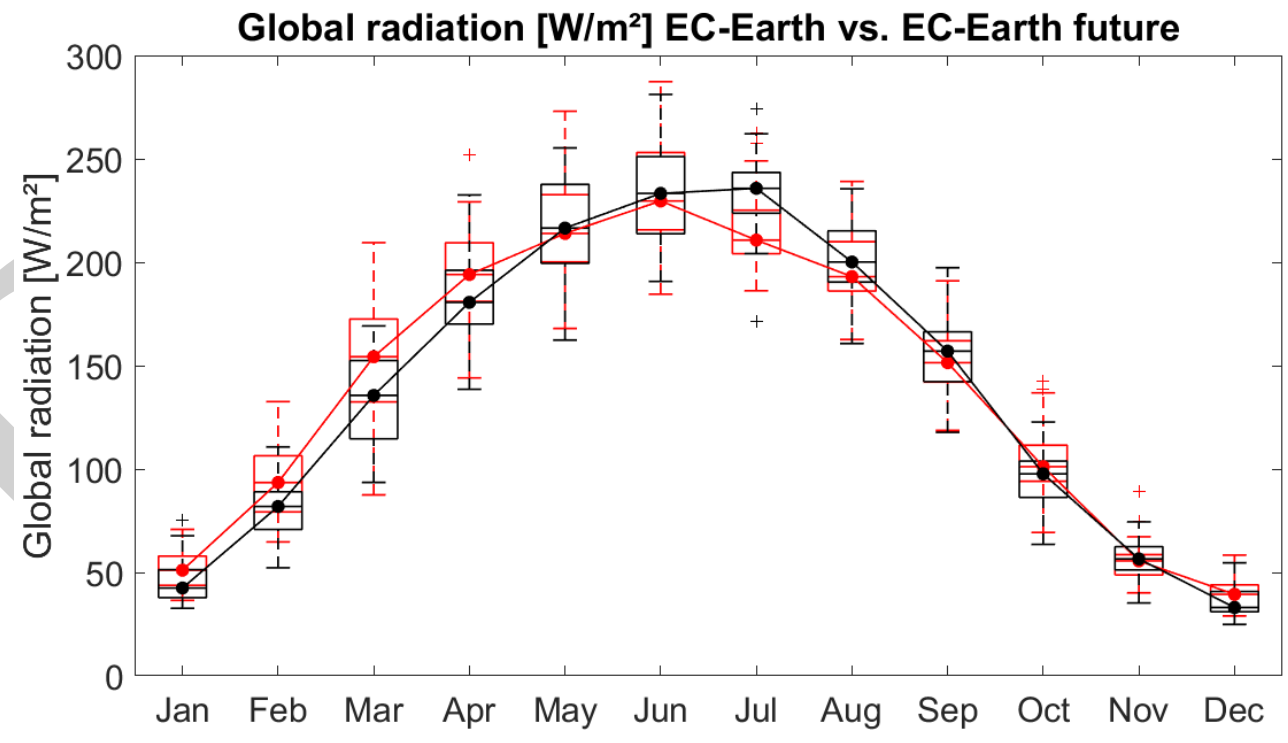

Fig. 3. Distribution monthly global radiation for EC-Earth (1976-2004 - red) and EC-Earth Future (2070-2098 - black) 
Secondly, some one-year weather files are generated from the climate models for ECEarth and EC-Earth Future. A Typical Meteorological Year (TMY) and a Typical Downscaled Year (TDY) are selected as typical years. The TMY methodology selects per month the most typical year from the climate model data based on the FinkelsteinSchafer statistics. Radiation and dry-bulb temperature each get a contribution of $40 \%$ in the weighting of the climate variables, wind speed and dew-point temperature a contribution of $10 \%$ each [61]. The TDY methodology applies the same FinkelsteinSchafer statistics, but only based on dry-bulb temperature [21].

As the TDY, ECY and EWY only use dry-bulb temperature as variable to determine the representativeness of the months, the good fit of these years with the mean and extreme temperatures of the 30 -year period is expected (Fig.4).

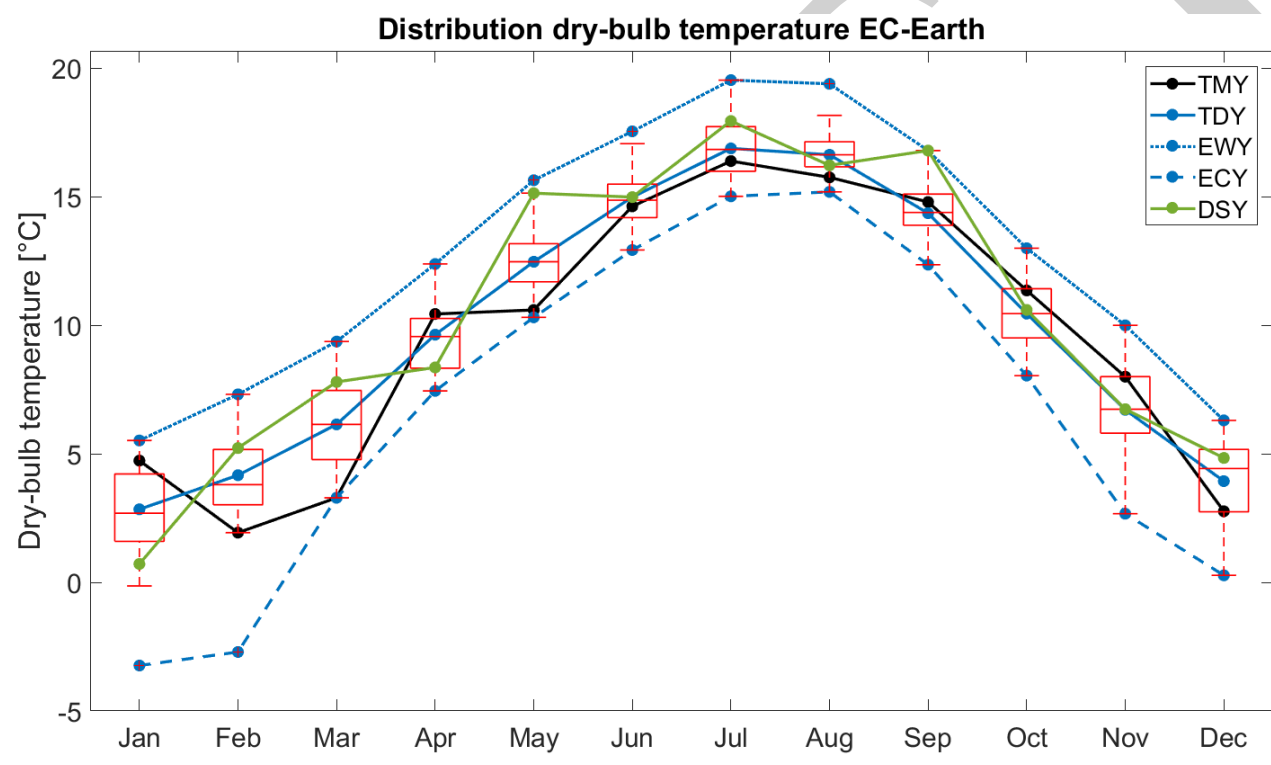

Fig. 4. Temperature distribution EC-Earth (1976-2004) with monthly mean Typical Meteorological Year (TMY), Typical Downscaled Year (TDY), Extreme Warm Year (EWY), Extreme Cold Year (ECY) and Design Summer Year (DSY)

Although the TMY considers both radiation and temperature to select the most representative months, some deviations are visible for the temperature. For radiation, the TMY has a good fit with the median values over the 30 -year period. In general, the TDY also has a good fit with the 30-year period (Fig. 5. ), however, with some values falling out of the range of the first to third quartile of the 30-year distribution (e.g. October). As the TDY is only selected on temperature, some deviations were expected. The ECY and EWY both have monthly values for radiation within the upper and lower percentiles of the 30-year distribution for the EC-Earth run. However, for EC-Earth future run (Fig. 6.), both the ECY and EWY have monthly global radiation values close to the extremes of the 30-year distribution (e.g. September for ECY, October for EWY). 


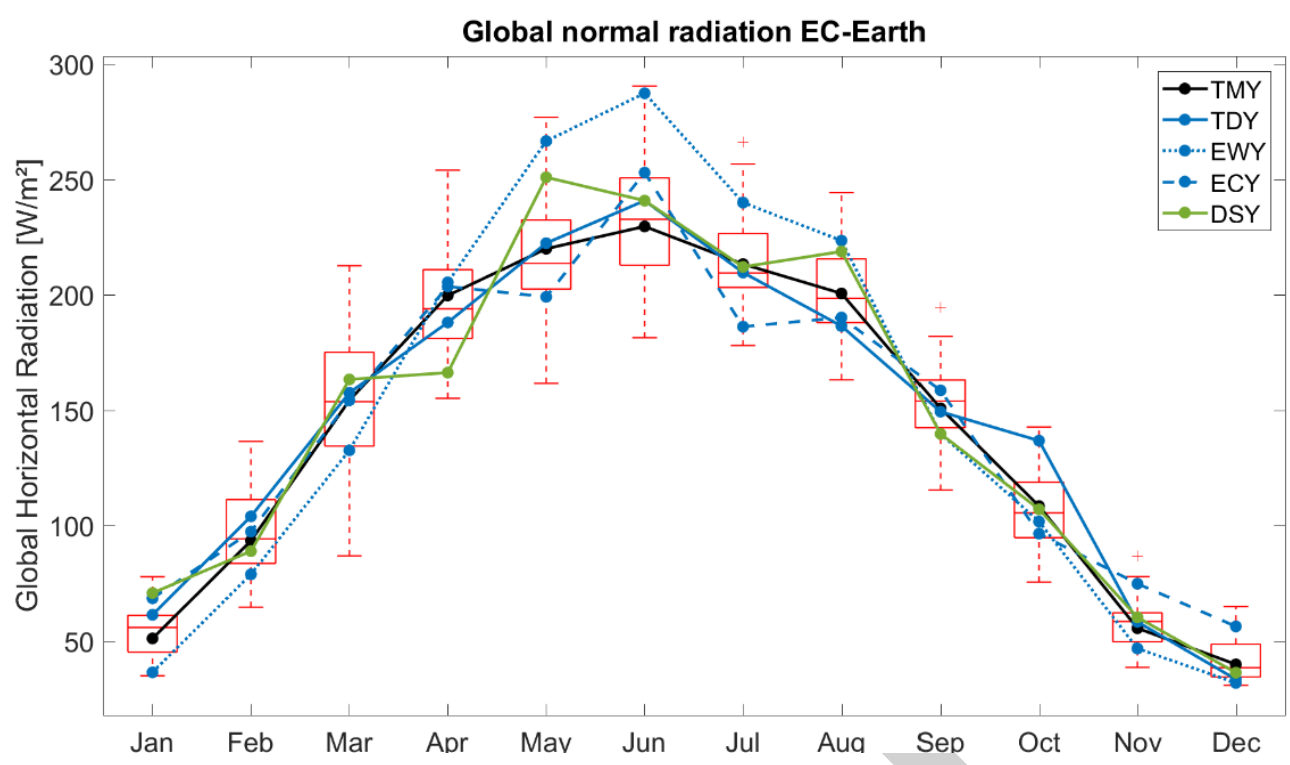

Fig. 5. Global radiation distribution EC-Earth (1976-2004) with monthly mean Typical Meteorological Year (TMY), Typical Downscaled Year (TDY), Extreme Warm Year (EWY), Extreme Cold Year (ECY) and Design Summer Year (DSY)

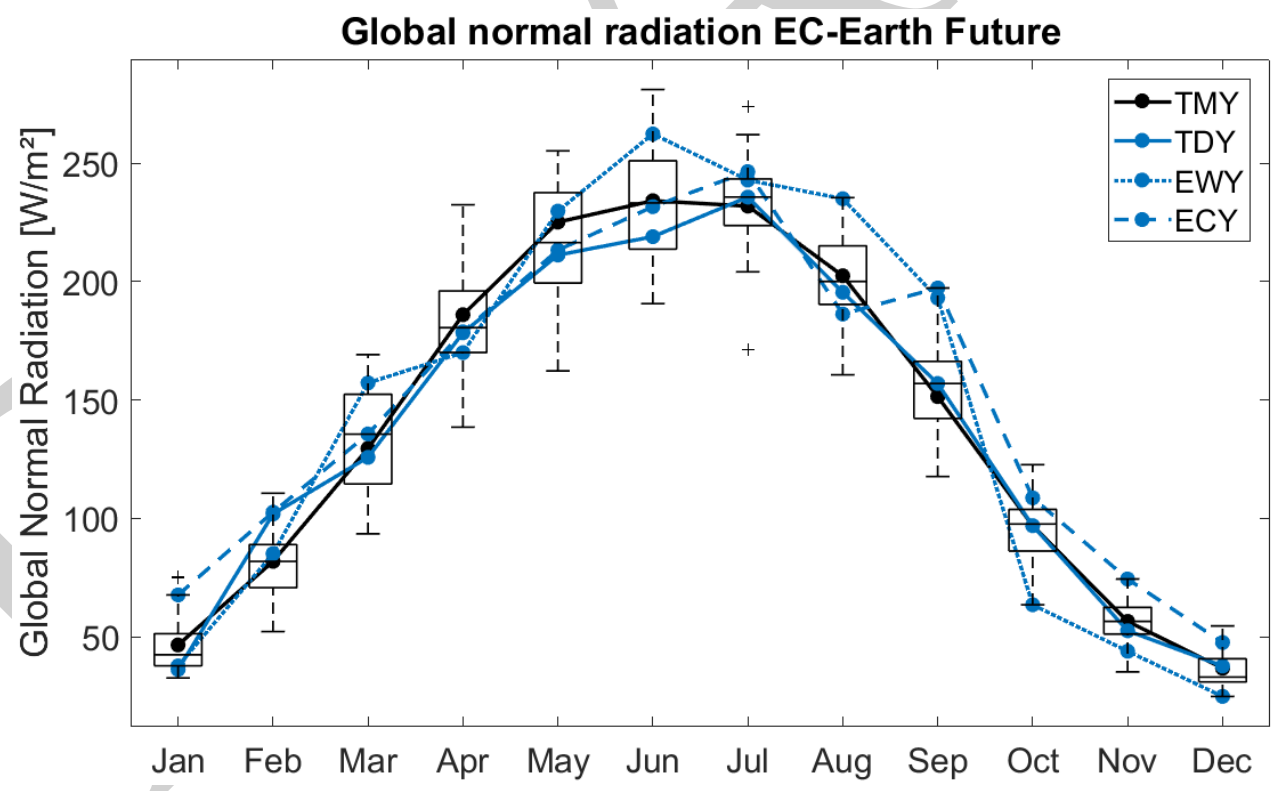

Fig. 6. Global radiation distribution EC-Earth Future (2070-2098) with monthly mean Typical Meteorological Year (TMY), Typical Downscaled Year (TDY), Extreme Warm Year (EWY) and Extreme Cold Year (ECY) 


\subsection{Energy demand}

In this simulation an ideal air loads system with an unlimited capacity is used. Consequently, the temperature setpoints are always met and the energy demand for heating and cooling gives an idea of the energy need for the thermal comfort for that period (e.g. higher cooling demand for months with higher temperatures).

For the monthly heating load, Fig. 7 shows that the heating load calculated with the TDY corresponds well with the median monthly heating load for the 30 -years of the climate model. For the TMY, the heating load often falls out of the 25-75th percentile of the 30-year calculation. Further, the ECY gives a good representation of the maximum heating load of the 30-year calculation and the EWY for the minimum. These observations also hold true for the other orientations and EC-Earth Future simulation.

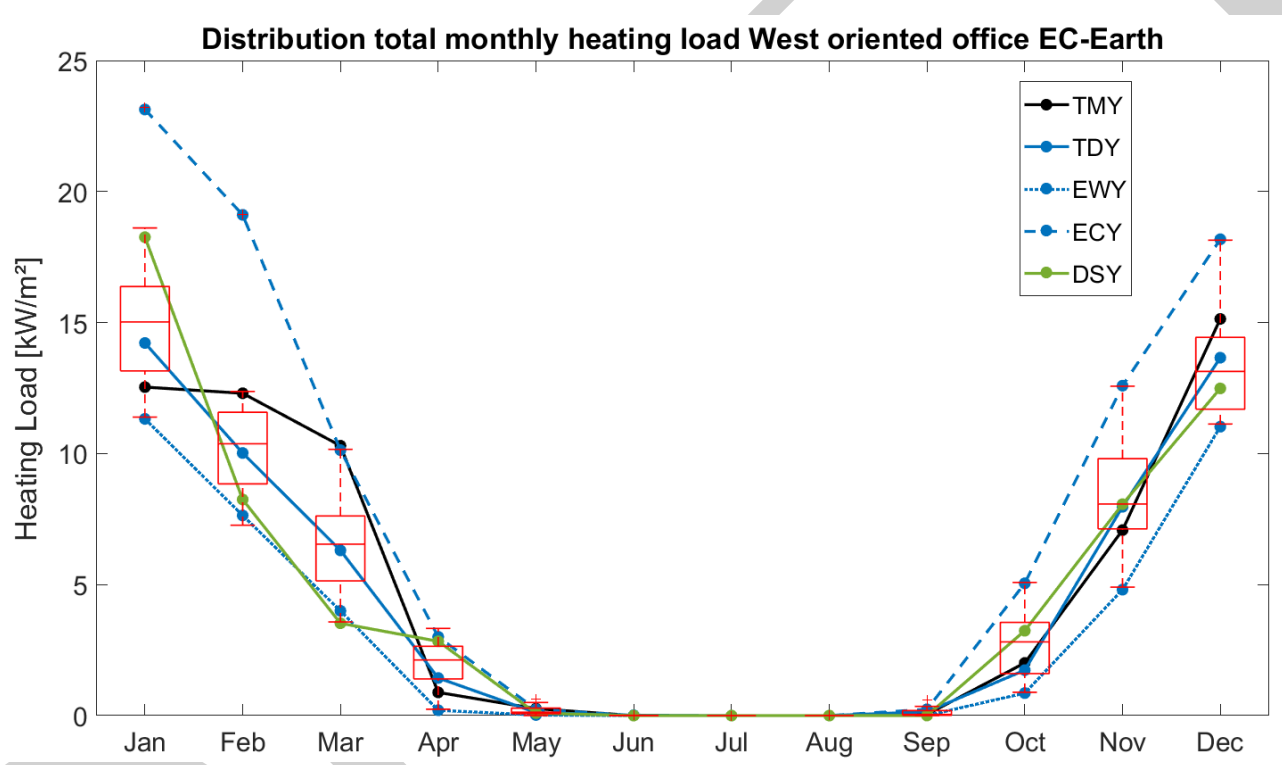

Fig. 7. Distribution total monthly heating load EC-Earth (1976-2004) and total monthly heating load for Typical Meteorological Year (TMY), Typical Downscaled Year (TDY), Extreme Warm Year (EWY), Extreme Cold Year (ECY) and Design Summer Year (DSY)

For the monthly cooling load, the TDY and TMY result in loads mostly within the 25 th75th percentile of the 30-year climate model results (Fig. 8 and Fig. 9). For both the EC Earth and EC Earth Future the DSY tends to underestimate the maximal cooling load. This is caused by the methodology to select a DSY. A full year is selected based on the average temperature from April to September. Consequently, an on average warm year is selected, however not necessarily a year with a lot of heatwave periods, which is the case for Uccle. These can also occur in a summer with a lower average temperature. Therefore, these years can be missed in the selection of the DSY.

Looking to the ability of the EWY to represent the maximum cooling load, an overall good fit is observed. In some cases (e.g. September in the EC-Earth simulation), the 
EWY underestimates the maximum cooling load even though a month with a higher average temperature is selected for the EWY. Moreover, in the September case of the EC-Earth simulation this month even had some days fulfilling heatwave requirements (minimum temperature above $18.2^{\circ} \mathrm{C}$ and maximum temperature above $29.6^{\circ} \mathrm{C}$ [2]). In this case the lower cooling need is caused by some days with a very low temperature and in addition lower irradiation on the façade.

The ECY represents the minimum cooling load overall well. However, for the ECEarth Future (Fig. 9) a higher cooling load then expected (e.g. September) is often reported. For September, this can be explained by the high radiation in the ECY for that month (Fig. 6. ) mainly caused by the direct component of the radiation. Hence, the internal heat gains through the windows increase and cause the higher cooling need. A similar explanation is found for October, however, the monthly radiation is lower which results in a lower resulting cooling load.

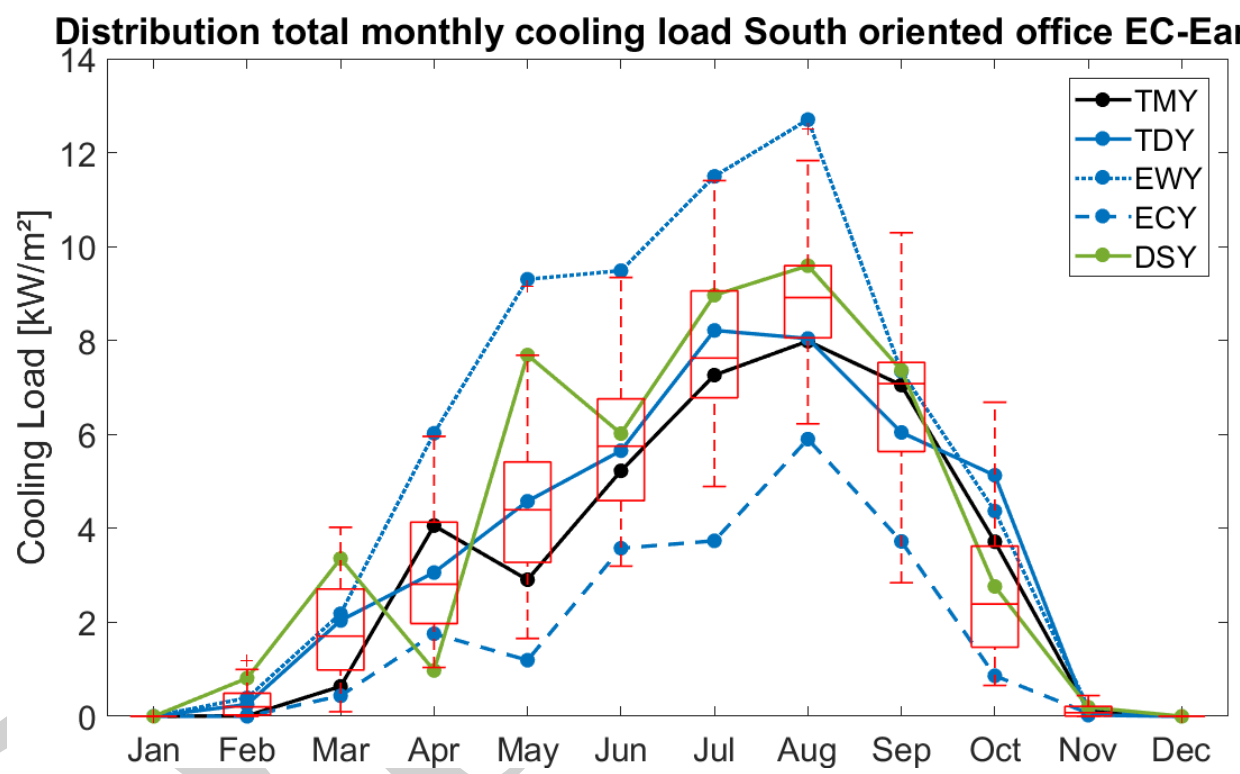

Fig. 8. Distribution total monthly cooling load for EC-Earth (1976-2004) and total monthly cooling load for Typical Meteorological Year (TMY), Typical Downscaled Year (TDY), Extreme Warm Year (EWY), Extreme Cold Year (ECY) and Design Summer Year (DSY) 


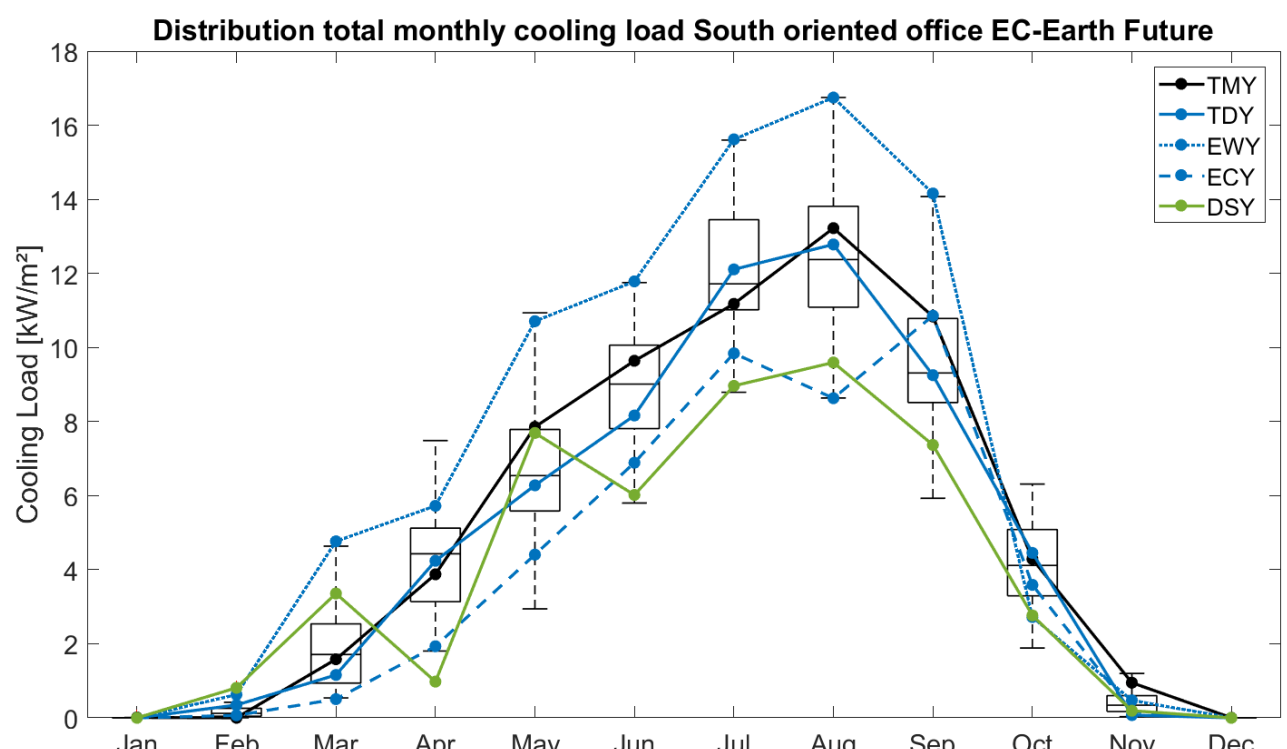

Fig. 9. Distribution total monthly cooling load for EC-Earth Future (2070-298) and total monthly cooling load for Typical Meteorological Year (TMY), Typical Downscaled Year (TDY), Extreme Warm Year (EWY), Extreme Cold Year (ECY) and Design Summer Year (DSY)

In general, the 30-year climate models have the advantage to represent the climate variability over a longer period. A combination of one-year weather files (TDY, EWY and ECY) as proposed by Nik [21] to reduce computational time proved to capture the average climate over the 30-years as well as the extreme climate events for the current and future climate conditions. However, some deviations for the ECY in the EC-Earth Future run were found.

For the average heating and cooling load differences are identified between the different one-year weather files (TDY and TMY) where the TDY results in a better agreement with the median 30-year loads for current and future climate conditions. The consideration of radiation in the TMY seems less important for Uccle.

For the extreme cooling load, the DSY leads to an underestimation of the maximal cooling load over 30-years caused by the selection based on an average temperature for April till September. Extreme heat wave periods can happen during an on average cool summer.

\section{Conclusion, critical reflections and outlook}

This chapter provides an overview of common methods to create future weather data and widely used weather datasets which can be used to assess the energy and thermal comfort performance of buildings under climate change for Belgium. In addition, recently developed future weather data files for Belgium were used to analyze the energy performance of a representative Flemish office room. The future weather data were 
generated from a recently developed convection-permitting climate model (CPM) for Belgium and consist of a Typical Meteorological Year (TMY), Typical Downscaled Year (TDY), Design Summer Year (DSY), Extreme Warm Year (EWY) and Extreme Cold Year (ECY). For reasons of representation both a CPM for the current and future climate conditions were used in the case study. The results obtained were moreover compared with results retrieved when using the existing future weather datasets.

Based on the analysis of the advantages and disadvantages of the methods to create future weather data, climate models and weather generators are identified as the most preferred for the estimation of the average energy consumption and thermal comfort in average and extreme situations. Climate models have the advantage to provide insights in future climate conditions with a meteorological consistency. In particular, Regional Climate models downscaled to a convection-permitting scale (CPMs with a resolution $<4 \mathrm{~km}$ ) allow to represent climate differences due to territorial settings (e.g. city versus sub-urban versus rural area) and better represent extreme weather events. The drawback of these models is however that they represent only one climate realization. Weather generators are interesting as they can generate multiple climate realizations with a limited computational time. The use of statistical relations in this methodology however can lead to meteorological inconsistencies. Further research is needed to investigate how both methodologies can be combined to keep the detailed representation of local climate processes and combine this with climate change uncertainties.

Looking at different weather datasets, one-year weather files represent average or extreme weather conditions (respectively typical and extreme weather years). To capture the climate variability, these files need to be combined in so-called synthesized weather data files. This was illustrated for the Belgian situation by combining a TDY with an EWY and ECY for the location of Uccle, as proposed in the methodology of Nik [21]. This resulted in an overall good representation of the energy need for heating and cooling in average and extreme weather conditions.

The influence of the methodological choices to extract these one-year weather files from the 30-year climate data is highlighted as different results were obtained when different meteorological variables were considered for the creation of the one-year files. Differences in average energy need were for example obtained when using TDY (created based on dry-bulb temperature) and a TMY (selected based for dry-bulb temperature, radiation, wind speed and humidity). Furthermore, the use of a DSY (full year selected based on average temperature April-September) underestimates extreme warm weather events and leads to an underestimation of the energy need for cooling compared to the median cooling load for the 30-years of the climate model. Finally, an ECY, expected to provide insights in the minimum cooling loads, led to higher cooling loads than expected based on the 30-years climate model. As the selection of an extreme cold month in the ECY weather data file is only based on temperature, still high radiation values can occur leading to a higher cooling need. 


\section{Acknowledgements}

This chapter is part of an $\mathrm{SBO} \mathrm{PhD}$ fellowship 'Towards future-proof buildings in Flanders: Climate and Life Cycle modelling for resilient office buildings' (1S97418N) funded by Research Foundation Flanders (FWO).

\section{References}

1. Vandentorren, S., Bretin, P., Zeghnoun, A., Mandereau-Bruno, L., Croisier, A., Cochet, C., Ribéron, J., Siberan, I., Declercq, B., Ledrans, M.: August 2003 heat wave in France: Risk factors for death of elderly people living at home. Eur. J. Public Health. 16, 583-591 (2006). doi:10.1093/eurpub/ck1063

2. Wouters, H., Ridder, K. De, Poelmans, L., Willems, P., Brouwers, J., Hosseinzadehtalaei, P., Tabari, H., Broucke, S. Vanden, van Lipzig, N.P.M., Demuzere, M.: Heat stress increase under climate change twice as large in cities as in rural areas : A study for a densely populated midlatitude maritime region. Geophys. Res. Lett. 44, 1-11 (2017). doi:10.1002/2017GL074889

3. Kovats, R.S., Valentini, R., Bouwer, L.M., Georgopoulou, E., Jacob, D., Martin, E., Rounsevell, M., Soussana, J.F.: Europe. In: Barros, V.R., Field, C. b., Dokken, D.., Mastrandrea, M.., Mach, K.J., Bilir, T.E., Chatterjee, M., Ebi, K.L., Estrada, Y.O., Genova, R.C., Girma, B., Kissel, E.S., Levy, A.N., MacCracken, S., Mastrandrea, P.R., and White, L.. (eds.) Climate Change 2014: Impacts, Adaptation and Vulnerability - Contributions of the Working Group II to the Fifth Assessment Report. pp. 1267-1326. Cambridge University Press, Cambridge, United Kingdom and New York, USA (2014)

4. Berger, T., Amann, C., Formayer, H., Korjenic, A., Pospischal, B., Neururer, C., Smutny, R.: Impacts of climate change upon cooling and heating energy demand of office buildings in Vienna, Austria. Energy Build. 80, 517-530 (2014). doi:10.1016/j.enbuild.2014.03.084

5. Crawley, D.B.: Estimating the impacts of climate change and urbanization on building performance. J. Build. Perform. Simul. 1, 91-115 (2008). doi:10.1080/19401490802182079

6. Andrić, I., Pina, A., Ferrão, P., Fournier, J., Lacarrière, B., Le Corre, O.: The impact of climate change on building heat demand in different climate types. Energy Build. 149, (2017). doi:10.1016/j.enbuild.2017.05.047

7. Shen, P.: Impacts of climate change on U.S. building energy use by using downscaled hourly future weather data. Energy Build. 134, 61-70 (2017). doi:10.1016/j.enbuild.2016.09.028

8. Shibuya, T., Croxford, B.: The effect of climate change on office building energy consumption in Japan. Energy Build. 117, (2016). doi:10.1016/j.enbuild.2016.02.023

9. Kershaw, T., Eames, M., Coley, D.: Assessing the risk of climate change for buildings: A comparison between multi-year and probabilistic reference year simulations. Build. Environ. 46, 1303-1308 (2011). doi:10.1016/j.buildenv.2010.12.018

10. Brotas, L., Nicol, F.: Architectural Science Review Estimating overheating in European dwellings. Archit. Sci. Rev. 603, 180-191 (2017). doi:10.1080/00038628.2017.1300762

11. Chow, D.H.C., Levermore, G.J.: The effects of future climate change on heating and cooling demands in office buildings in the UK. Build. Serv. Eng. Res. Technol. 31, 307-323 (2010)

12. de Wilde, P., Tian, W.: Predicting the performance of an office under climate change: A 
study of metrics, sensitivity and zonal resolution. Energy Build. 42, 1674-1684 (2010). doi:10.1016/j.enbuild.2010.04.011

13. Farrou, I., Kolokotroni, M., Santamouris, M.: Building envelope design for climate change mitigation: a case study of hotels in Greece. Int. J. Sustain. Energy. 1-24 (2014). doi:10.1080/14786451.2014.966711

14. Holmes, M.J., Hacker, J.N.: Climate change, thermal comfort and energy: Meeting the design challenges of the 21st century. Energy Build. 39, 802-814 (2007). doi:10.1016/j.enbuild.2007.02.009

15. MBE KTN: Guidance for making the case for climate change adaptation in the built environment. (2013)

16. Nik, V.M., Sasic Kalagasidis, A.: Impact study of the climate change on the energy performance of the building stock in Stockholm considering four climate uncertainties. Build. Environ. 60, 291-304 (2013). doi:10.1016/j.buildenv.2012.11.005

17. RICS: Climatic Risk Toolkit. The impact of climate change in the Non-Domestic Real Estate sector of eight European countries. (2015)

18. EnergyPlus: EnergyPlusTM Version 8.7 Documentation: Auxiliary Programs, (2016)

19. Barnaby, C.S., Crawley, D.B.: Weather data for building performance simulation. In: Building perfomance simulation for design and operation (2011)

20. ASHRAE: Chapter 14, Climatic Design Information. In: ASHRAE Handbook-Fundamentals (2017)

21. Nik, V.M.: Making energy simulation easier for future climate - Synthesizing typical and extreme weather data sets out of regional climate models (RCMs). Appl. Energy. 177, 204 226 (2016). doi:10.1016/j.apenergy.2016.05.107

22. IPCC: Climate Change 2013: The Physical Science Basis. Contribution of Working Group I to the Fifth Assessment Report of the Intergovernmental Panel on Climate Change. CUP, Cambridge, United Kingdom and New York, USA (2013)

23. Jentsch, M.F., Bahaj, A.S., James, P.A.B.: Climate change future proofing of buildingsGeneration and assessment of building simulation weather files. Energy Build. 40, 21482168 (2008). doi:10.1016/j.enbuild.2008.06.005

24. Jentsch, M.F., James, P.A.B., Bourikas, L., Bahaj, A.S.: Transforming existing weather data for worldwide locations to enable energy and building performance simulation under future climates. Renew. Energy. 55, 514-524 (2013). doi:10.1016/j.renene.2012.12.049

25. Jones, P., Harpham, C., Kilsby, C., Glenis, V., Burton, A.: UK Climate Projections science report: Projections fo future daily climate for the UK from the Weather Generator. (2010)

26. Levermore, G., Courtney, R., Watkins, R., Cheung, H.K.W., Parkinson, J.B., Laycock, P., Natarajan, S., Nikolopoulou, M., McGilligan, C., Muneer, T., Tham, Y., Underwood, C.P., Edge, J.S., Du, H., Sharples, S., Kang, J., Barclay, M., Sanderson, M.: Deriving and using future weather data for building design from UK climate change projections - an overview of the COPSE Project. 1-7 (2014)

27. Nik, V.M.: Application of typical and extreme weather data sets in the hygrothermal simulation of building components for future climate - A case study for a wooden frame wall. Energy Build. 154, 30-45 (2017). doi:10.1016/j.enbuild.2017.08.042

28. Eames, M., Kershaw, T., Coley, D.: On the creation of future probabilistic design weather years from UKCP09. Build. Serv. Eng. Res. Technol. 32, 127-142 (2011). doi:10.1177/0143624410379934 
29. Struck, C., de Wilde, P., Evers, J., Hensen, J.L.M., Plokker, W.: On selecting weather data sets to estimate a building design's robustness to climate variations. Proc. 11th IBPSA Build. Simul. Conf. 513-520

30. Chan, A.L.S.: Developing future hourly weather files for studying the impact of climate change on building energy performance in Hong Kong. Energy Build. 43, 2860-2868 (2011). doi:10.1016/j.enbuild.2011.07.003

31. Liu, C., Kershaw, T., Eames, M.E., Coley, D.A.: Future probabilistic hot summer years for overheating risk assessments. Build. Environ. 105, 56-68 (2016). doi:10.1016/j.buildenv.2016.05.028

32. Narowski, P., Janicki, M., Heim, D.: Comparison of untypical meteorological years (umy) and their influence on building energy performance simulations. In: Proceedings of BS 2013: 13th Conference of the International Building Performance Simulation Association. pp. 1414-1421 (2013)

33. Belcher, S., Hacker, J., Powell, D.: Constructing design weather data for future climates. Build. Serv. Eng. Res. Technol. 26, 49-61 (2005). doi:10.1191/0143624405bt112oa

34. CIBSE: Use of climate change scenarios for building simulation : the CIBSE future weather years Use of climate change scenarios for building simulation: the CIBSE future weather years. (2009)

35. Jacob, D., Petersen, J., Eggert, B., Alias, A., Christensen, O.B., Bouwer, L.M., Braun, A., Colette, A., Déqué, M., Georgievski, G., Georgopoulou, E., Gobiet, A., Menut, L., Nikulin, G., Haensler, A., Hempelmann, N., Jones, C., Keuler, K., Kovats, S., Kröner, N., Kotlarski, S., Kriegsmann, A., Martin, E., van Meijgaard, E., Moseley, C., Pfeifer, S., Preuschmann, S., Radermacher, C., Radtke, K., Rechid, D., Rounsevell, M., Samuelsson, P., Somot, S., Soussana, J.F., Teichmann, C., Valentini, R., Vautard, R., Weber, B., Yiou, P.: EUROCORDEX: New high-resolution climate change projections for European impact research. Reg. Environ. Chang. 14, 563-578 (2014). doi:10.1007/s10113-013-0499-2

36. Wilby, R.L., Wigley, T.M.L.: Downscaling general circulation model output: a review of methods and limitations. Prog Phys Geog. 21, 530-548 (1997). doi:10.1177/030913339702100403

37. Moss, R., Babiker, M., Brinkman, S., Calyo, E., Carter, T., Edmonds, J., Elgizouli, I., Emori, S., Erda, L., Hibbard, K., Jones, R., Kainuma, M., Kelleher, J., Lamarque, J.F., Manning, M., Matthews, B., Meehl, J., Meyer, L., Mitchell, J., Nakicenovic, N., O’Neill, B., Pichs, R., Riahi, K., Rose, S., Runci, P., Stouffer, R., Vuuren, D. van, Weyant, J., Wilbanks, T., Ypersele, J.P. van, Zurek, M.: Towards New Scenarios for Analysis of Emissions, Climate Change, Impacts and Response Strategies. (2008)

38. Brisson, E., Demuzere, M., Willems, P., van Lipzig, N.P.M.: Assessment of natural climate variability using a weather generator. Clim. Dyn. 44, 495-508 (2014). doi:10.1007/s00382014-2122-8

39. Nik, V.M., Coccolo, S., Kämpf, J., Scartezzini, J.L.: Investigating the importance of future climate typology on estimating the energy performance of buildings in the EPFL campus. Energy Procedia. 122, 1088-1093 (2017). doi:10.1016/j.egypro.2017.07.434

40. Kikumoto, H., Ooka, R., Arima, Y., Yamanaka, T.: Study on the future weather data considering the global and local climate change for building energy simulation. Sustain. Cities Soc. 14, 404-413 (2015). doi:10.1016/j.scs.2014.08.007

41. Brisson, E., Van Weverberg, K., Demuzere, M., Devis, A., Saeed, S., Stengel, M., van Lipzig, 
N.P.M.: How well can a convection-permitting climate model reproduce decadal statistics of precipitation, temperature and cloud characteristics? Clim. Dyn. 47, 3043-3061 (2016). doi:10.1007/s00382-016-3012-z

42. Wouters, H., De Ridder, K., Poelmans, L.: Heat stress increase towards the mid-21st century twice as large for cities compared to rural areas. (2016)

43. Kendon, E.J., Ban, N., Roberts, N.M., Fowler, H.J., Roberts, M.J., Chan, S.C., Evans, J.P., Fosser, G., Wilkinson, J.M.: Do convection-permitting regional climate models improve projections of future precipitation change? Bull. Am. Meteorol. Soc. 98, 79-93 (2017). doi:10.1175/BAMS-D-15-0004.1

44. Prein, A.F., Langhans, W., Fosser, G., Ferrone, A., Ban, N., Goergen, K., Keller, M., Tölle, M., Gutjahr, O., Feser, F., Brisson, E., Kollet, S., Schmidli, J., Van Lipzig, N.P.M., Leung, R.: A review on regional convection-permitting climate modeling: Demonstrations, prospects, and challenges. Rev. Geophys. 53, 323-361 (2015). doi:10.1002/2014RG000475

45. Wilks, D.S., Wilby, R.L.: The weather generation game: a review of stochastic weather models. Prog. Phys. Geogr. 23, 329-357 (1999). doi:10.1191/030913399666525256

46. Van Paassen, A.H.C., Luo, Q.X.: Weather data generator to study climate change on buildings. Build. Serv. Eng. Res. Technol. 23, 251-258 (2002). doi:10.1191/0143624402bt048oa

47. Adelard, L., Boyer, H., Garde, F., Gatina, J., Adelard, L., Boyer, H., Garde, F., Detailed, J.G.: Detailed weather data generator for building simulations To cite this version : HAL Id : hal00765831 A DETAILLED WEATHER DATA GENERATOR FOR BUILDINGS SIMULATION. 31, 75-88 (2012)

48. Herrera, M., Natarajan, S., Coley, D.A., Kershaw, T., Ramallo-González, A.P., Eames, M., Fosas, D., Wood, M.: A review of current and future weather data for building simulation. Build. Serv. Eng. Res. Technol. 014362441770593 (2017). doi:10.1177/0143624417705937

49. Hutchinson, M.F.: Methods of generation of weather sequences. In: Bunting, A.H. (ed.) Agricultural environments: Characterization, Classification and Mapping. Wallingford, UK: CAB International (1987)

50. Berger, T., Amann, C., Formayer, H., Korjenic, A., Pospichal, B., Neururer, C., Smutny, R.: Impacts of urban location and climate change upon energy demand of office buildings in Vienna, Austria. Build. Environ. 81, 258-269 (2014). doi:10.1016/j.buildenv.2014.07.007

51. Wouters, H., De Ridder, K., Demuzere, M., Lauwaet, D., Van Lipzig, N.P.M.: The diurnal evolution of the urban heat island of Paris: A model-based case study during Summer 2006. Atmos. Chem. Phys. 13, 8525-8541 (2013). doi:10.5194/acp-13-8525-2013

52. Kolokotroni, M., Ren, X., Davies, M., Mavrogianni, A.: London's urban heat island: Impact on current and future energy consumption in office buildings. Energy Build. 47, 302-311 (2012). doi:10.1016/j.enbuild.2011.12.019

53. CIBSE: TM36: Climate change and the indoor environment: impacts and adaptation. Charted Inst. Build. Serv. Eng. (2005)

54. Ferrari, D., Lee, T.: Beyond Tmy : Climate Data for Specific Applications. Sol. Energy. 112 (2008)

55. Roetzel, A., Tsangrassoulis, A.: Impact of climate change on comfort and energy performance in offices. Build. Environ. 57, 349-361 (2012). doi:10.1016/j.buildenv.2012.06.002

56. Finkelstein, J.M., Schafer, R.E.: Improved goodness-of-fit tests. Biometrika. 58, 641-645 
(1971). doi:10.1093/biomet/58.3.641

57. National Climate Data Center, U.S. Dept. of Commerce: Test Reference Year. Tape Ref. Man. TD-9706, (1976)

58. Kershaw, T., Eames, M., Coley, D. a: Comparison of multi-year and reference year building simulations. Build. Serv. Eng. Res. Technol. 31, 357-369 (2010). doi: $10.1177 / 0143624410374689$

59. International organization for Standardization: 15927-4 Hygrothermal performance of buildings -- Calculation and presentation of climatic data -- Part 4: Hourly data for assessing the annual energy use for heating and cooling., Geneva (2005)

60. Didier, J., Alfred, P.: The development of typical weather years for international locations : Part I , algorithms. (2002)

61. Huang, Y.J., Su, F., Seo, D., Krarti, M.: Development of 3012 IWEC2 weather files for international locations (RP-1477). ASHRAE Trans. 120, 340-355 (2014)

62. Stoffel, T.L., Rymes, M.D.: Production of the weather year for energy calculations version 2 (WYEC2) data files. In: ASHRAE Transactions. pp. 487-497 (1998)

63. European Commission (EC): Test Reference Years TRY, Weather data sets for computer simulations of solar energy systems and energy consumption in buildings., Brussels, Belgium (1985)

64. ASHRAE: Brussels 064510 (IWEC), (2002)

65. Thevenard, D.J., Brunger, A.P.: The development of Typical Weather Years for International Locations : Part II , Production. ASHRAE Trans. 480-486 (2002)

66. Meteotest: Remund, J., Müller, S., Kunz, S., Huguenin-Landl, B., Studer, C., Cattin, R.: Meteonorm Handbook part I: Software, Global Meteorological Database Version 7 Software and Data for Engineers, Planers and Education, http://www.meteonorm.com, (2017)

67. Levermore, G.J., Doylend, N.O.: North American and European Hourly Based Weather Data and Methods for HVAC Building Energy Analyses and Design by Simulation. ASHRAE Trans. 108, 1053-1062 (2002)

68. Lee, K., Yoo, H., Levermore, G.J.: Generation of typical weather data using the ISO Test Reference Year (TRY) method for major cities of South Korea. Build. Environ. 45, 956-963 (2010). doi:10.1016/j.buildenv.2009.10.002

69. Deutscher Wetterdienst: Handbuch Ortsgenaue Testreferenzjahre von zukünftige Witterungsverhältnisse. 45 (2017)

70. Wilcox, S., Marion, W.: Users Manual for TMY3. Renew. Energy. (2008). doi:NREL/TP581-43156

71. Marion, W., Urban, K.: User`s manual for TMY2s: Derived from the 1961--1990 National Solar Radiation Data Base. (1995)

72. Eames, M.E., Ramallo-Gonzalez, A.P., Wood, M.J.: An update of the UK's test reference year: The implications of a revised climate on building design. Build. Serv. Eng. Res. Technol. 37, 316-333 (2015). doi:10.1177/0143624415605626

73. Crawley, D.: Which weather data should you use for energy simulations of commercial buildings? Am. Soc. Heat. Refrig. Air-conditioning. 1-18 (1998)

74. CIBSE: CIBSE Guide J: Weather, Solar and Illuminance Data. Chart. Inst. Build. Serv. Eng. 455 (2002)

75. CIBSE: Design Summer Years for London Design Summer Years for London. TM49. (2014)

76. Watkins, R., Levermore, G.J., Parkinson, J.B.: The design reference year - A new approach 
to testing a building in more extreme weather using UKCP09 projections. Build. Serv. Eng. Res. Technol. 34, 165-176 (2013). doi:10.1177/0143624411431170

77. Ramon, D., Wouters, H., Lipzig, N. Van, Allacker, K.: Comparison of high-resolution climate model data with a Test Reference Year for building simulations. In: Brotas, L., Roaf, S., and Nicol, J.F. (eds.) Proceedings of 33rd PLEA International Conference. pp. 18651872. NCEUB 2017 (2017)

78. Communities \& Local Government: National Calculation Methodology (NCM) modelling guide (for buildings other than dwellings in England and Wales). Communities local Gov. 1-34 (2008)

79. Architectenvenootschap ar-te bcvba: BelOrta

80. ASHRAE: ASHRAE Handbook-Fundamentals. ASHRAE Handbook-Fundamentals. 21.121.67 (2009). doi:10.1017/CBO9781107415324.004

81. Hazeleger, W., Severijns, C., Semmler, T., Ştefănescu, S., Yang, S., Wang, X., Wyser, K., Dutra, E., Baldasano, J.M., Bintanja, R., Bougeault, P., Caballero, R., Ekman, A.M.L., Christensen, J.H., Van Den Hurk, B., Jimenez, P., Jones, C., Kållberg, P., Koenigk, T., McGrath, R., Miranda, P., Van Noije, T., Palmer, T., Parodi, J.A., Schmith, T., Selten, F., Storelvmo, T., Sterl, A., Tapamo, H., Vancoppenolle, M., Viterbo, P., Willén, U.: EC-Earth: A seamless Earth-system prediction approach in action. Bull. Am. Meteorol. Soc. 91, 13571363 (2010). doi:10.1175/2010BAMS2877.1

82. Vanden Broucke, S., Wouters, H., Demuzere, M., van Lipzig, N.P.M.: Added value of convection-permitting scale in simulating future change in extreme precipitation (Under review). (2017)

83. Wouters, H., Demuzere, M., Blahak, U., Fortuniak, K., Maiheu, B., Camps, J., Tielemans, D., Van Lipzig, N.P.M.: The efficient urban canopy dependency parametrization (SURY) v1.0 for atmospheric modelling: Description and application with the COSMO-CLM model for a Belgian summer. Geosci. Model Dev. 9, 3027-3054 (2016). doi:10.5194/gmd-9-30272016

84. Höppe, P.: The physiological equivalent temperature - A universal index for the biometeorological assessment of the thermal environment. Int. J. Biometeorol. 43, 71-75 (1999). doi:10.1007/s004840050118 